\title{
Neuronal Migration Disorders: A Contribution of Modern Neuroimaging to the Etiologic Diagnosis of Epilepsy
}

\author{
André Palmini, Frederick Andermann, André Olivier, Donatella Tampieri, Yvon Robitaille, \\ Denis Melanson and Romeo Ethier
}

\begin{abstract}
Computed tomography and magnetic resonance imaging enable the identification of neuronal migration disorders during life. Several specific syndromes have been identified and early diagnosis of previously unrecognized entities is now possible. We report 51 patients with imaging. Thirty-two had a single widespread cortical dysplastic lesion. Twenty-eight had focal corticectomies. From a pathological standpoint, these encompassed focal cortical dysplasia (14 cases) and forme fruste of tuberous sclerosis (10 cases). These two groups of patients were indistinguishable from the clinical and radiological standpoint. In only two was the MRI examination normal. In addition, there were 10 with bilateral perisylvian dysplasia, four with diffuse cortical dysplasia or the "double cortex" syndrome, three with hemimegalencephaly, one with megalencephaly, and one with nodular neuronal heterotopia. The electroclinical and imaging findings led to the development of specific surgical strategies for the alleviation of the intractable seizures in each of these radiologically-defined syndromes.

RÉSUMÉ: Anomalies de la migration neuronale: contribution de l'imagerie moderne au diagnostic étiologique de l'épilepsie. Le scanner $X$ et la résonance magnétique (RM), permettent d'identifier, pendant la vie, certaines anomalies de la migration neuronale. Plusieurs syndromes spécifiques ont été identifiés et leur diagnostic précoce est maintenant possible. Notre étude porte sur un groupe de 51 malades, ayant été étudiés par RM et/ou scanner X. Trentedeux avaient des lésions dysplasiques corticales isolées; vingt-huit ont subi des cortectomies focales. Les examens anatomo-pathologiques ont révélé une dysplasie corticale focale dans 14 cas et une forme fruste de sclérose tubéreuse dans 10 cas. Ces deux groupes de malades ne pouvaient pas être différenciés à partir des seules données cliniques et radiologiques. Seulement deux d'entre eux avient une RM normale. En plus, 10 malades avec une dysplasie perisylvienne bilatérale, 4 avec une dysplasie corticale diffuse (ou syndrome du "double cortex"), 3 avec une hémi-mégalencéphalie, 1 avec mégalencéphalie, et 1 avec des hétérotopies neuronales nodulaires ont été étudiés. Ces trouvailles cliniques, électroencéphalographiques et radiologiques ont rendu possible la mise au point d'approches chirurgicales spécifiques, visant un meilleur contrôle des crises rebelles associées à chacun de ces syndromes.
\end{abstract}

Can. J. Neuol. Sci. 1991; 18: 580-587

One of the most important factors since early attempts to classify the epilepsies has been the presence of a recognizable cause for a given epileptic disorder. ${ }^{1,2}$ The distinction between idiopathic and symptomatic epilepsies has evolved throughout the years in a dynamic fashion, as more sophisticated neurodiagnostic tools have become available.

Modern neuroimaging techniques, particularly magnetic resonance imaging (MRI), have made it possible to recognize during life abnormalities in the process of neuronal migration, that are usually accompanied by epilepsy. 3.9

Neuronal migration disorders (NMD) result from derangements in the process through which neuroblasts proliferating in the peri-ventricular germinal matrix reach their final, pre-programmed position in the cerebral cortex. This process of neu- ronal migration extends from the 8th to the 24th gestational week, with successive generations of neurons migrating towards progressively more superficial layers in the neocortex, and is responsible for the final cytoarchitectonic organization of the cortical mantle in layers and columns. ${ }^{10-13}$

Depending on the timing, location, and extent of the interference with the normal migration processes, different types of NMDs of varying configuration and severity will ensue. These have first been described according to the pathological findings, since only post-mortem diagnosis was then possible. 14-21

The advent of modern neuroimaging techniques not only permitted early diagnosis of these entities during life; it has also set the stage for the delineation of an anatomically or radiologically defined classification of the NMDs. The correlation between

From the Department of Neurology and Neurosurgery, McGill University and the Montreal Neurological Institute and Hospital, Montreal Dr. Palmini's present address: Serviço de Neurologia, Hospital São Lucas-PUC, Av. lpiranga 6690, Porto Alegre, RS, Brasil, 90610 Reprint requests to: Dr. Andermann, Montreal Neurological Institute, 3801 University Street, Montreal, Quebec, Canada H3A 2B4 
these different forms of NMD with clinical and EEG data has, in turn, allowed identification of specific syndromes, with epilepsy as a major manifestation. $3,4,22-25$

We present a review of the different types of NMD, as delineated by neuroimaging techniques based on the study of 51 patients evaluated for intractable epilepsy at the Montreal Neurological Hospital from 1975 to the present. For each type of NMD, we outline the relationship between radiological and pathological findings, as well as the electro-clinical correlations of the associated epileptic disorder. Different surgical approaches for treatment of the intractable seizures are then presented.

\section{Patients and Methods}

Forty-nine of the 51 patients presented with epilepsy. Their ages at evaluation, seizure onset, and the duration of the epileptic disorder ranged respectively from 1 to 35 (mean, 18.1), 1 to 28 (mean, 5.3), and 1 to 30 years (mean, 12.1). The two nonepileptic patients were siblings, seen at ages 26 and 30 respectively.

In all patients sixteen channel extracranial EEGs using the 10-20 system were recorded directly or by cable telemetry. Flexible, silver-wire sphenoidal electrodes suitable for longterm use were inserted. Prolonged recordings during wakefulness and sleep, and, more recently, intensive EEG video-monitoring with automatic spike and seizure detection programs were employed. ${ }^{26}$ The extent of epileptic EEG abnormalities was judged according to the areas containing interictal spiking in at least two EEG recordings.

Neuropsychological studies including intracarotid sodium amobarbital testing were carried out according to established protocols. ${ }^{27,28}$ All patients had CT scans (12 with an EMI 1010, and 39 with a GE 9800 machine) and 32 had MRI (5 with a 0.5 Tesla Philips Gyroscan, and 27 with a 1.5 Tesla Philips Gyroscan). TI weighted images were obtained using TR 450 and TE 30. Proton density and T2 weighted images in the patients studied with the $0.5 \mathrm{~T}$ scanner were obtained using TR
1500 and TE 30 and 60 , respectively. In the patients studied with the $1.5 \mathrm{~T}$ scanner, proton density and $\mathrm{T} 2$ weighted images were obtained using TR 2100 and TE 30 and 60 , respectively.

Thirty-seven patients were treated surgically: 33 had excisions of epileptogenic tissue and 4 had anterior callosotomies.

The anatomical extent of the structural lesions was judged according to both the neuroimaging findings and the appearance of the brain at operation. Autopsy studies were available in one patient.

Macroscopic and microscopic examinations of surgical specimens were performed in all operated patients for diagnosis and sub-typing of NMDs. Diagnosis could not be made in 8 patients since the most abnormal tissue was not available for pathological examination: 5 had resections of epileptogenic tissue and 3 had anterior callosotomies. In these, the diagnosis of NMD was based on imaging studies and the macroscopic appearance of the lesion at surgery. In one of the patients who had a callosotomy, a right frontal biopsy was also performed.

\section{Results}

Five distinct entities were identified, based on the anatomical or imaging distribution of the NMDs: (1) focal cortical dysplastic lesions $(n=32)$; (2) bilateral perisylvian dysplasia $(n=10)$; (3) diffuse cortical dysplasia ("double cortex" syndrome) $(n=$ 4); (4) hemimegalencephaly/megalencephaly $(n=4)$; and (5) nodular grey matter heterotopia $(n=3 ; 2$ of these patients also had focal cortical dysplastic lesions). A comparison between the radiological and the pathological classifications of NMDs is shown in Table 1.

\section{Focal Cortical Dysplastic Lesions}

This group consisted of 32 patients with partial epilepsy. Antiepileptic medication controlled the seizures satisfactorily (though never completely) in only four. The other 28 were therefore treated surgically. The diagnosis was confirmed by pathological study or intraoperative cortical visualization.

Table 1: Radiological and pathological features of NMDs associated with intractable epilepsy

\begin{tabular}{ll}
\hline \hline Radiological Classification (MRI) & Histopathological Classification \\
\hline 1. Focal Cortical Dysplastic Lesions & - Focal Cortical Dysplasia \\
- macrogyric or polymicrogyric appearance & - Forme Fruste of Tuberous Sclerosis \\
& - Pachygyria \\
& - Polymicrogyria \\
2. Bilateral Perisylvian Dysplasia & - Polymicrogyria \\
- polymicrogyric appearance & - Subcortical Grey Matter \\
3. Diffuse Cortical Dysplasia & Band (Laminar) Heterotopia \\
- lissencephalic or diffusely pachygric appearance & \\
- "double cortex" appearance & - Pachygyria \\
4. Hemimegalencephaly/Megalencephaly & - Polymicrogyria \\
- macrogyric, polymicrogyric & - Subcortical Nodular Grey Matter \\
and heterotopic appearance & Heterotopia
\end{tabular}

5. Nodular and Laminar Heterotopias

- heterotopic appearance

- Subcortical Nodular or Laminar
Heterotopia 
Fifteen patients had MRI. In 8, an area of focal macrogyria, characterized by increased cortical thickness, shallow sulci and abnormal grey/white matter transition was seen (Figure 1). In an additional patient MRI showed an area of focal polymicrogyria, characterized by almost normal cortical thickness and grey/white matter differentiation with multiple small gyri separated by almost imperceptible shallow sulci (Figures 2A, B). Therefore, in 9 of the 15 or $60 \%$ of patients with focal cortical dysplastic lesions the MRI detected the cortical abnormality.

In the remaining 6 patients, the MRI did not show the area of cortical abnormality, although 4 had macrogyria on direct cortical visualization. Three of them had a region of increased signal in subcortical white matter, detected by proton density and T2 weighted images, and the fourth had a mass of subcortical nodular neuronal heterotopia with the same signal intensity as the cortical mantle.

The MRI was completely normal in 2 patients, even after the injection of Gadolinium in one. This patient, a 13-year-old girl, had elementary visual seizures with rapid secondary generalization, and a left parieto-occipital epileptogenic area. A focal area of decreased cerebral blood flow in the same region was detected by HMPAO-SPECT scan in the interictal state.

The other patient with initially normal examination and normal MRI had intractable partial motor status epilepticus involving the left face, hand, arm, and occasionally the leg lasting uninterruptedly for 5 months. EEGs showed practically continuous epileptic activity from the right central region. Two excisions of tissue surrounding the central area did not alter the seizures, and the tissue sampled was histologically normal. A third corticectomy with resection of the central region stopped

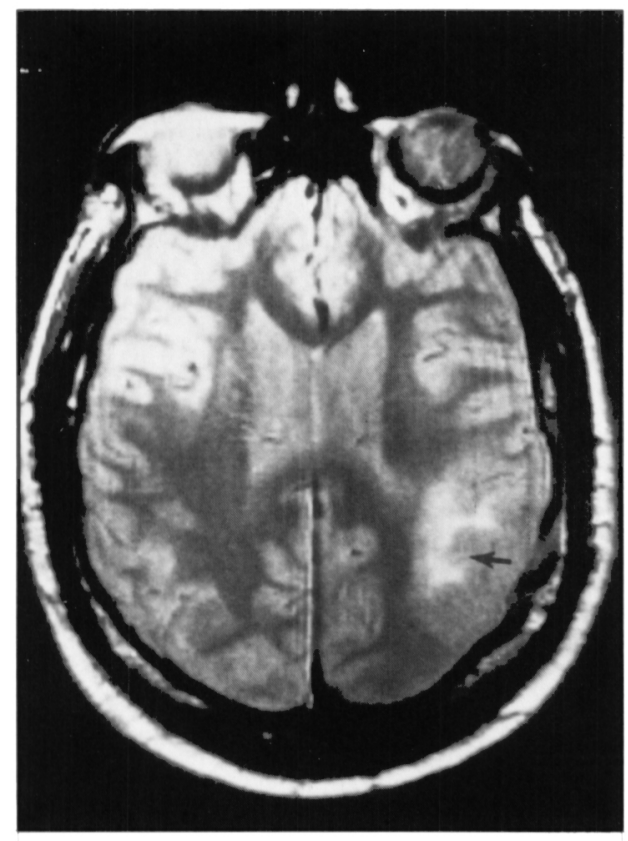

Figure 1-Proton density MRI image (TR 2100, TE 30) in the axial view of a 35-year-old man with mild congenital right hemiparesis and partial sensorimotor seizures involving the right leg. Note focal area of increased cortical thickness and poor sulcation in the left parietal region representing macrogyria (arrow), associated with hyperintense signal in the subcortical white matter. the seizures. The resected central strip showed the changes of focal cortical dysplasia.

All patients had CT scans. The older generation EMI 1010 scanner did not show definite cortical abnormality in any of the 12 patients studied. In 10 of the $19(53 \%)$ studied with the GE 9800 scanner a focal area of increased cortical or grey matter thickness was seen. These included 5 of the 8 patients with macrogyria on MRI, the one patient with polymicrogyria on MRI and 4 patients who were not studied with MRI.

CT did not show the subcortical increased signal nor the details of the polymicrogyric cortex (Figure 2C), (though an area of cortical abnormality was apparent). The subcortical grey matter heterotopia were also not visualized.

Histopathological examination was available for 24 patients: 14 were diagnosed as having focal cortical dysplasia (FCD) 29 and 10 had the forme fruste of tuberous sclerosis (FFTS). ${ }^{30}$ In all cases the isocortex displayed high density of haphazardly distributed, large neurons, the size of Betz cells and glial cells, associated with variable disorganization of horizontal cortical lamination. The four-layered cortex characteristic of pachygyria was never seen. Thus it appears that a focal increase in cortical thickness on imaging studies (macrogyria) can be due to three different forms of NMD: FCD, FFTS, and true pachygyria, the latter recognized by Barkovitch et al. ${ }^{4}$ and by Byrd et al..$^{5}$ but not found in this group of patients.

There were no major differences in the clinical or electrographic, nor in the radiological presentation of FCD and FFTS.

Age at seizure onset ranged from 1 to 21 years (mean 6.8). In this group, $67 \%$ had complex partial and $73 \%$ partial motor attacks. Three-quarters of the patients had secondarily generalized seizures, and $27 \%$ had tonic or atonic drop attacks. Ten patients had a history of status epilepticus, 5 of them partial motor. Only $34 \%$ had an epileptic zone restricted to one lobe or area of the brain. These were central in 3 , frontal in 3 , and temporal in 5 . Three additional patients had bitemporal and 2 bifrontal epileptic discharges. The remaining $50 \%$ had widespread unilateral epileptic areas.

In only 6 of the 28 operated patients was an apparently complete excision of the structural abnormality possible. In 22 cases, portions of the visible lesion encroaching upon important cortical regions could be excised.

\section{Bilateral Perisylvian Dysplasia}

A syndrome consisting of bilateral perisylvian cortical dysplasia, pseudobulbar palsy, secondary generalized epilepsy, and mental retardation has recently been recognized. ${ }^{25}$ This entity has also been referred to by the eponym developmental FoixMarie-Chavany syndrome. ${ }^{3 !}$

Eight of our 10 patients presented with epilepsy manifested by a combination of generalized convulsive and complex partial seizures, drop attacks, and less often, partial sensory attacks. In one patient we documented an unusual seizure pattern with bilateral peri-oral clonic movements. 32,33

EEG epileptiform abnormalities consisted of generalized slow spike-and-wave or poly-spike and wave complexes, associated with multifocal discharges.

The patients present with a pseudobulbar palsy, manifested by severe dysarthria and inability to protrude or move the tongue laterally. In addition, a mild, usually bilateral but often 
asymmetrical pyramidal syndrome and variable degrees of mental retardation may be present.

CT scans show thick bands of grey matter in the sylvian and rolandic areas of both hemispheres (Figure 3A). These were originally interpreted as representing macrogyria; however, MRI and clinico-pathological studies have shown that the cortical abnormality consists of polymicrogyria ${ }^{31,34}$ (Figure 3B).

Focal resective surgery is not feasible in these patients. When drop attacks constitute a significant disability, callosotomy is indicated, ${ }^{35}$ and was performed in two of our patients with good results.

Two patients did not have epilepsy. These were siblings from a family in which a maternal uncle had had a similar phenotype and died in status epilepticus. Why these two patients, unlike all the others, did not have seizures is not clear. The possibility that genetic factors may be involved in the genesis of this phenotype is an attractive hypothesis. A detailed report of this family is presented elsewhere. ${ }^{36}$

\section{Diffuse Cortical Dysplasia ("Double-Cortex" Syndrome)}

Four patients had a continuous layer of subcortical band heterotopia which was separated from the overlying cortical mantle by a thin layer of apparently normal white matter visualized on MRI22,35,38 (Figure 4). CT scans showed only diffusely increased cortical thickness and did not permit reliable diagnosis of this entity.

In the one patient who had a brain biopsy at the time of callosotomy, the subcortical band heterotopia was clearly demonstrated.
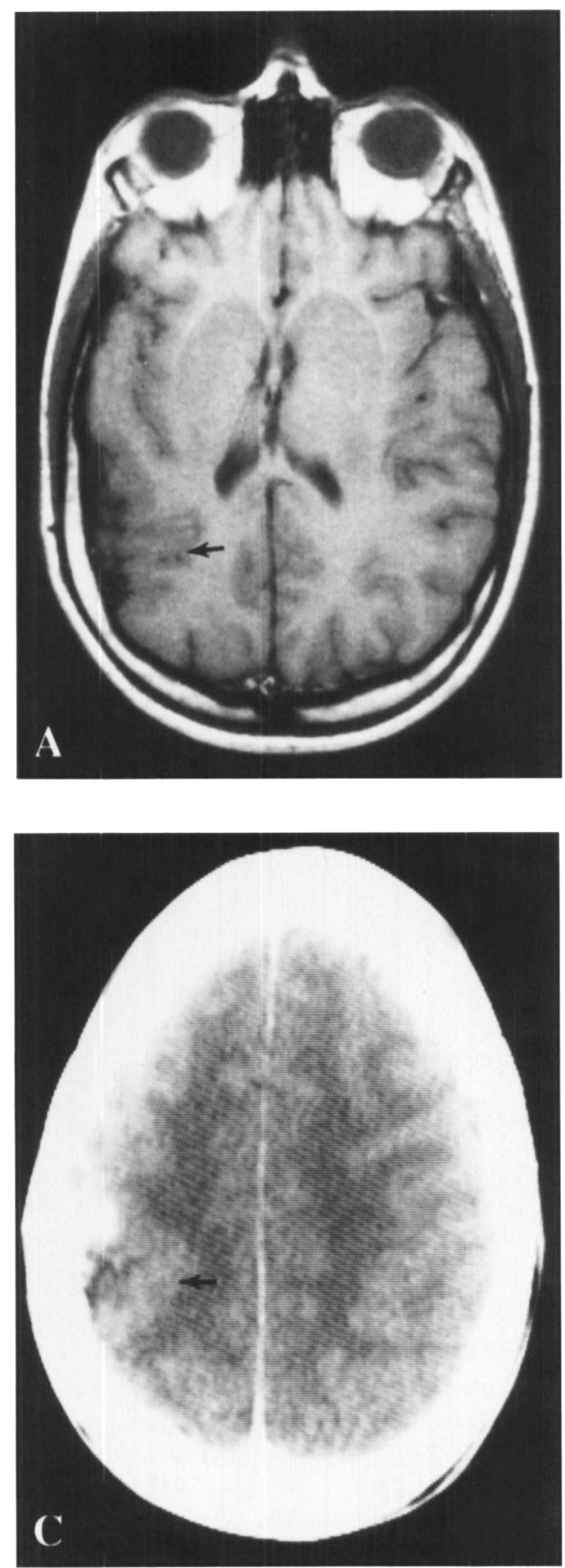

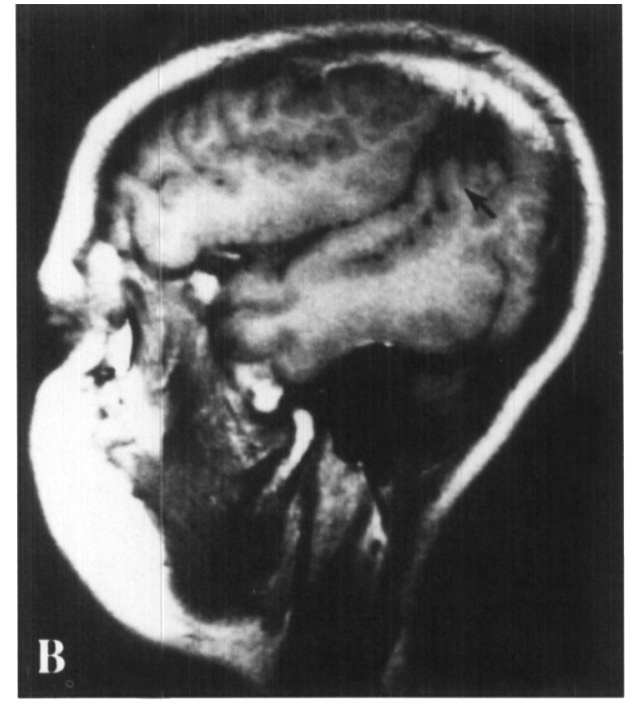

Figure 2 - Seventeen-year-old girl with partial motor seizures affecting the left hemibody. MRITI weighted image (TR 450,TE 30) in axial view (2A) show's an area of apparently increased cortical thickness and multiple, very small gyri packed together (polymicrogyria) in the right parietal lobe (arrow). In parasaggital view (2B) it can be appreciated that the area of polymicrogyria is adjacent to the posterior border of the sylvian fissure (arrow). $2 C$ is a contrast-enhanced CT scan. The cortex appears thicker (arrow), but the polymicrogyria is not demonstrated. 

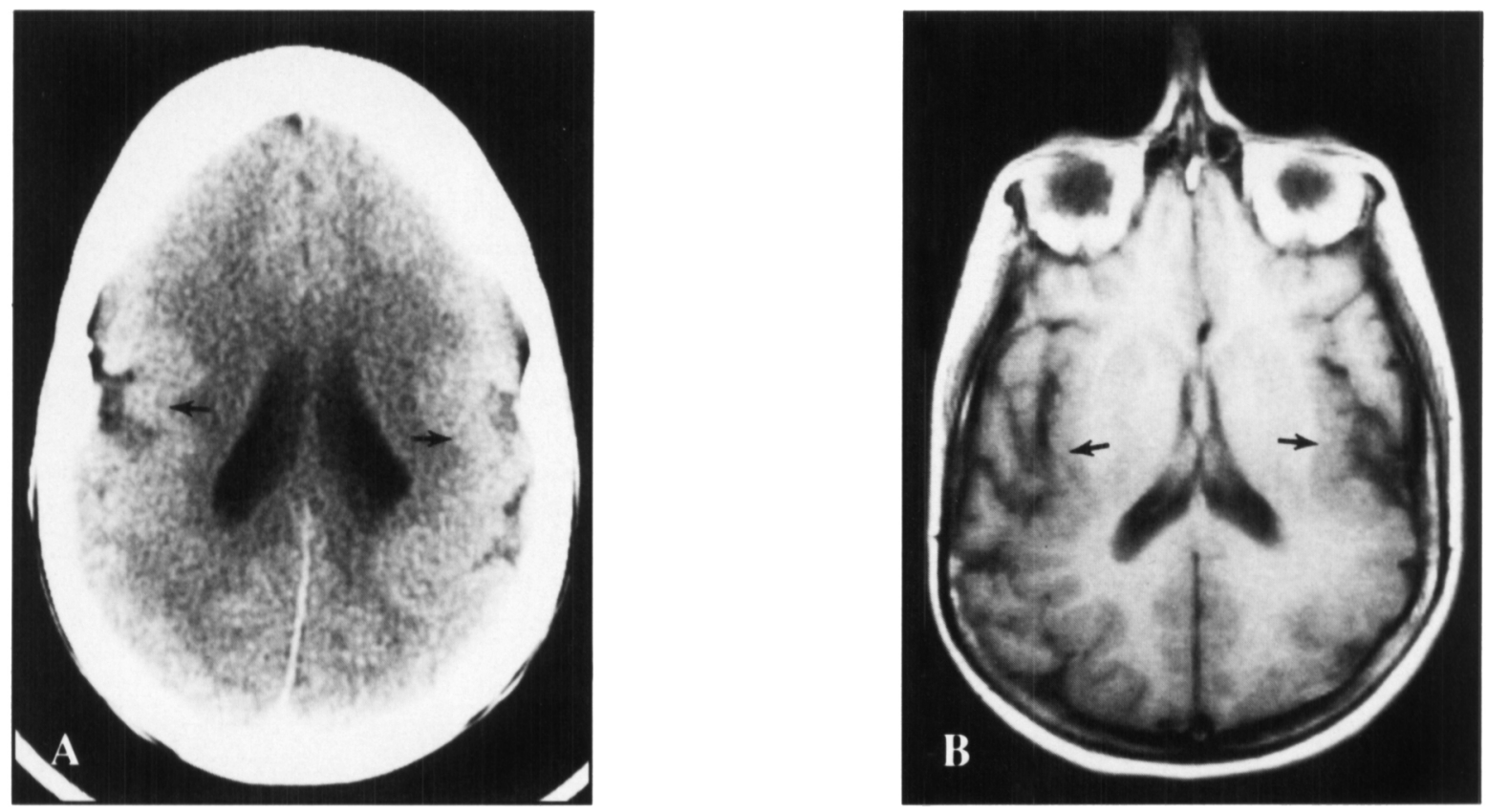

Figure 3 - Twenty-six-year-old woman with congenital pseudobulbar palsy, severe dysarthria and drop attacks. $3 \mathrm{~A}$ is a contrast-enhanced CT scan showing only symmetrical, thick cortex in both perisylvian regions (arrows). $3 B$ is a TI weighted MRI image (TR 450, TE 30) in the axial view demonstrating poor opercularization and the small gyri (polymicrogyria) bilaterally in the insular regions (arrows).

This architectonic abnormality was first described as a "double cortex" by Jakob in 1936.16 The overlying cortical mantle is either normal or only mildly thickened.

The clinical seizure patterns and the severity of the epilepsy vary widely. In our series, one patient presented with a typical Lennox-Gastaut syndrome; the other three had drop attacks, and partial seizures secondarily generalized. EEGs disclosed either generalized slow spike-and-wave, or multifocal epileptic discharges. There is also great variability in the degree of mental retardation. Our patient with the Lennox-Gastaut syndrome was severely retarded. Two others had FSIQ's between 40 and 80 , and the remaining one had an IQ greater than $\mathbf{8 0 .}$

Focal resections of epileptogenic tissue are not feasible in this syndrome. When drop attacks are present and lead to disability, anterior callosotomy is indicated. It was performed in two of our patients and led to improvement, particularly of the drop attacks.

In this syndrome we were able to document the major contribution of advanced neuroimaging. Three of the four patients were previously examined with an older MRI scanner, and found to have only diffusely increased cortical thickness. Two of them were the subject of a previous report and were described to have generalized cortical dysplasia. ${ }^{9}$ Later reexamination of these patients using a new $1.5 \mathrm{~T}$ scanner clearly showed the double cortex configuration. ${ }^{38}$

The radiological picture of continuous subcortical heterotopia associated with either a normal gyral pattern or only slight increase in cortical thickness with shallow sulci suggests that the derangement of neuronal migration, albeit diffuse, allows many neurons to reach the cortical surface. $15,39,40$ This syndrome, though more benign, appears to be related to the lissencephalies according to Pinard et al., who have shown these malformations to coexist in two families. ${ }^{41}$

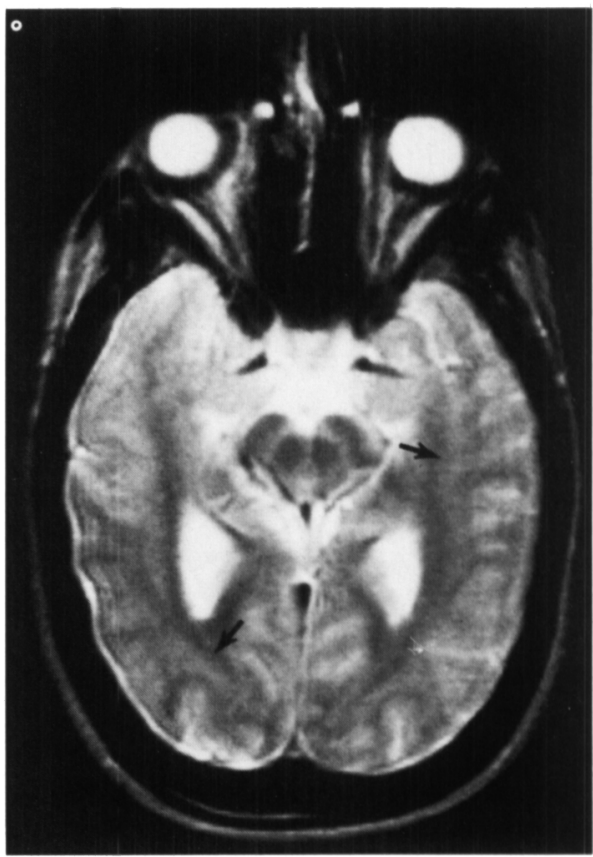

Figure 4-T2 weighted MRI image (TR 2100,TE 60) in the axial view of a 13-year-old girl with generalized convulsive seizures, drop attacks and mental retardation. Note the continuous linear band of subcortical heterotopia giving the "double cortex" appearance (arrows).

\section{Hemimegalencephaly/Megalencephaly}

In hemimegalencephaly the hemisphere and the ipsilateral ventricle are enlarged. 42 A variety of associated architectonic abnormalities of the brain, demonstrated by MRI, and confirmed on histopathological analysis includes pachygyria, polymicrogyria and neuronal heterotopias (Figure 5). 
Seizures were present in our 3 patients with this type of NMD, and were characterized by lateralized motor manifestations with secondary generalization and drop attacks. EEGs demonstrated large, unilateral epileptogenic areas, with occasional secondary bilateral synchrony.

The degree of motor disability found in patients with hemimegalencephaly is variable. Many have a marked hemiparesis with no finger movements, but this was not the case in any of our patients. All had only mild to moderate hemiparesis, and largely preserved finger movements; the seizures were the most disabling symptom.

When the motor disability is severe or obviously progressing to maximal hemiparesis, modified hemispherectomy may be considered. ${ }^{43}$ This was not the case in our 3 patients whose motor disability was only mild. Excision of the most active epileptogenic areas within the affected hemisphere produced substantial improvement in seizure control, but not complete cessation of the attacks.

Megalencephaly is a generalized malformation which may present with structural focal abnormalities, resulting in partial seizures. The one patient in our series had a head circumference of 25 ". The pre- and post-central gyri on one side were enlarged to double their size (Figure 6A) and showed continuous epileptogenic discharges in the EEG. These led to frequent partial motor seizures and drop attacks. Since the paresis was mild, the central area could not be excised. Recent MRI scans showed a similar appearance not associated with epileptogenic discharges contralaterally (Figure 6B).

\section{Nodular Grey Matter Heterotopias}

Failure of groups of neurons to initiate or complete their migration process results in nodular neuronal heterotopia

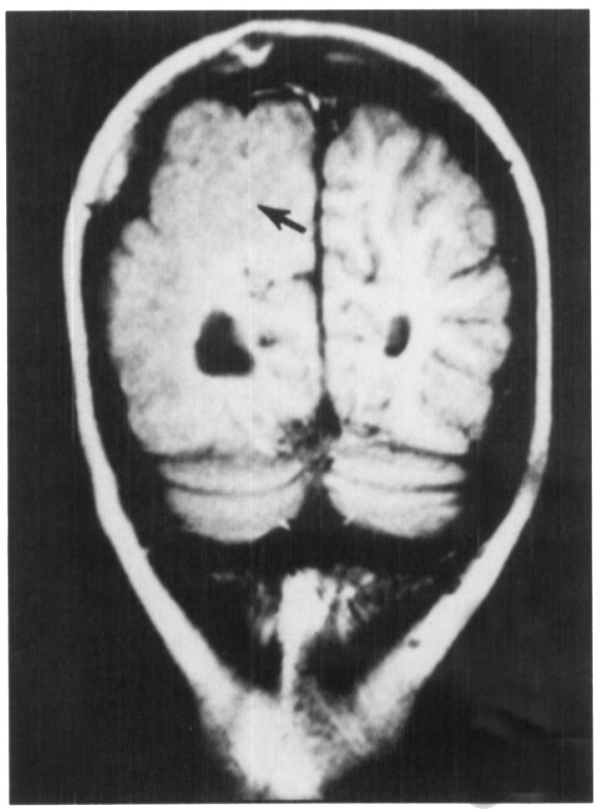

Figure 5 - Five-year-old boy with mild left hemiparesis and partial motor and secondarily generalized seizures. TI weighted MRI image (TR 450,TE 30) in the coronal view shows that the right hemisphere is bigger than the left, with associated increased cortical thickness and subcortical laminar heterotopias (arrow). There is also ventricular asymmetry. between the peri-ventricular surface and the cortical mantle.4.7 In periventricular nodular heterotopia the clumps of abnormally located neurons are seen on CT and MRI indenting the walls of the lateral ventricles (Figure 7). Nodular heterotopia due to arrest of neuronal migration anywhere between the ventricles and the cortex manifest as irregular grey matter aggregates in the subcortical white matter with the same signal intensity as the overlying cortical mantle on MRI (Figure 8).

Our one patient with periventricular nodular heterotopia had a clinical pattern suggesting temporal lobe epilepsy. Her mother also had epilepsy treated elsewhere by temporal lobectomy but no details were available.

Two patients with lateralized subcortical nodular heterotopia also had macrogyria in the overlying cortex. Both presented with partial motor seizures, secondarily generalized. Surgical resection of the cortical abnormality and the epileptogenic area led to improvement in the seizure frequency and severity.
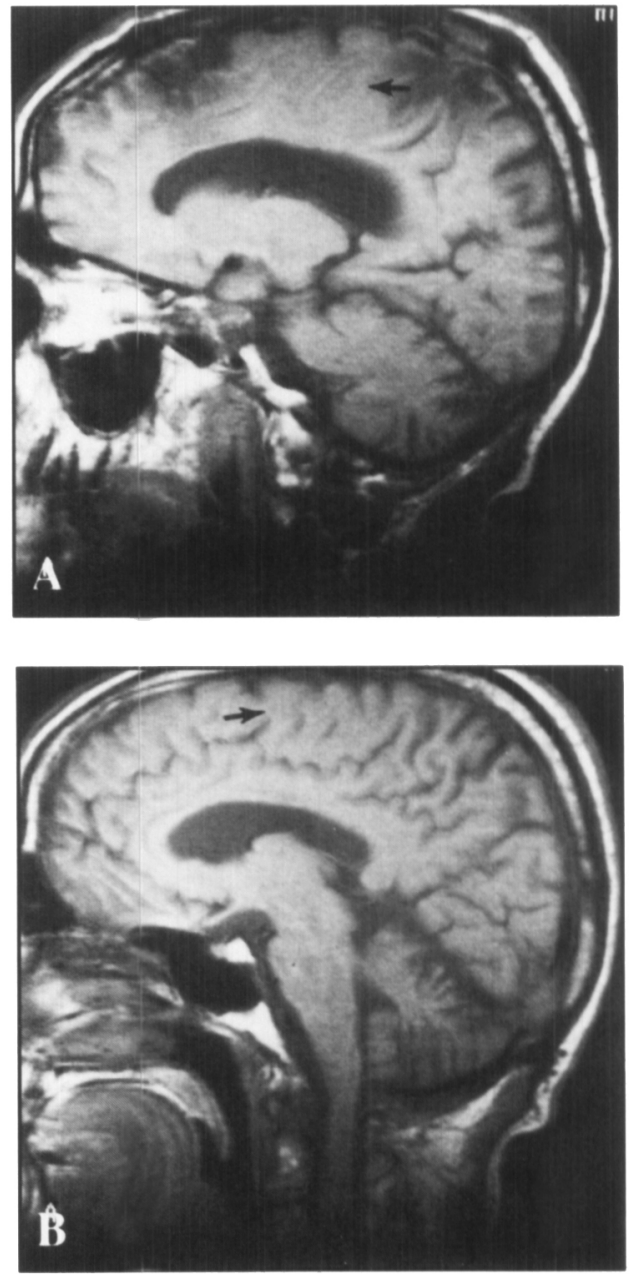

Figure 6 - Thirty-six year-old man with mild left hemiparesis, partial motor seizures and drop attacks. $6 A$ and $6 B$ are $T l$ weighted $M R I$ images (TR 450,TE 30) in the sagittal view of the right and left hemispheres, respectively. Note gross macrogyria in the right central region (arrow). This patient has had a corticectomy both anterior and posterior to the area of maximal abnormality. A much milder abnormality in sulcation is seen contralaterally $(6 B$. arrow). 


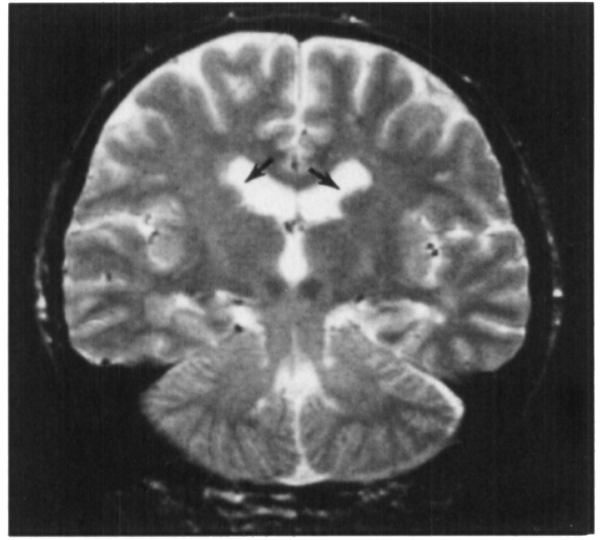

Figure $7-T 2$ weighted MRI image (TR 2100,TE 60) in the coronal plane of a 36-year-old woman with complex partial seizures. Note the indentations in the lumen of the ventricles due to clumps of heterotopic neurons (arrows).

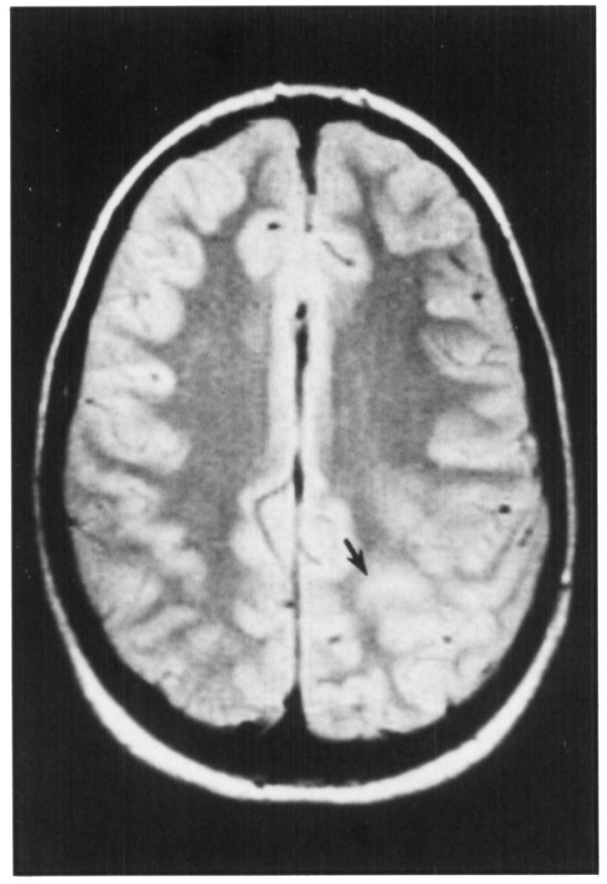

Figure 8-TI weighted MRI image (TR 450,TE 30) in the axial plane of a 9-year-old girl with frequent episodes of partial motor status epilepticus involving the right hand, arm and face, and secondarily generalized seizures. Note the massive nodular subcortical heterotopia in the left parietal lobe (arrow).

\section{Conclusion}

CT and especially MRI have greatly expanded the role of imaging in the understanding of patients with intractable epilepsy. Gliotic changes can be recognized and the high resolution of MRI has permitted the study of normal and pathological anatomy of small but important structures such as the hippocampus. The changes of Ammon's horn sclerosis can now be seen during life. Small "foreign tissue" lesions are now always or almost always identified preoperatively, an important aid in planning surgical treatment.
Cortical dysplasia, the forme fruste of tuberous sclerosis, bilateral perisylvian dysplasia with polymicrogyria, diffuse cortical dysplasia or the double cortex syndrome, hemimegalencephaly, nodular or laminar heterotopia, and schizencephaly can now be diagnosed by MRI. Recognition of the specific migration disorders allows correlation with the various epileptic syndromes associated with them and is particularly helpful in the planning of surgical therapy. ${ }^{44,45}$ However, in our last two patients cortical dysplasia could not even retrospectively be demonstrated by MRI, indicating that this diagnosis cannot unfailingly be made by current imaging studies.

In evaluation of patients, concordance of clinical EEG, neuropsychological, and functional imaging in addition to radiological and magnetic resonance studies is still required for optimal assessment of epileptic patients refractory to medical treatment.

\section{ACKNOWLEDGEMENT}

Supported in part by a grant from CAPES to Dr. Palmini.

\section{REFERENCES}

1. Commission for Classification and Terminology of the International League Against Epilepsy. Proposal for classifica. tion of epilepsies and epileptic syndromes. Epilepsia 1985; 26: 268-278.

2. Merlis J. Proposal for an international classification of the epilepsies. Epilepsia 1970; 11: 114-119.

3. Andermann F, Olivier A, Melanson D, et al. Epilepsy due to focal cortical dysplasia with macrogyria and the forme fruste of tuberous sclerosis: A study of 15 patients. In: Wolf P, Dam M, Janz D, Dreifuss FE, eds. vol. 16. New York: Raven Press, 1987; 35-38.

4. Barkovitch AJ, Chuang SH, Norman D. MR of neuronal migration anomalies. Am J Neuroradiol 1987; 8: 1009-1017.

5. Byrd SE, Osborn RE, Bohan TP, et al. The CT and MR evaluation of migrational disorders of the brain. Part 1. Lissencephaly and pachygyria. Pediatr Radiol 1989; 19: 151-156.

6. Byrd SE, Osborn RE, Bohan TP, et al. The CT and MR evaluation of migrational disorders of the brain. Part Il. Schizencephaly, heterotopia and polymicrogyria. Pediatr Radiol 1989; 19: 219 222.

7. Hayden SA, Davis KA, Stears JC, et al. MR Imaging of heterotopic grey matter. J Comput Assist Tomogr 1987; 11: 878-879.

8. Kuzniecky R, Berkovic S, Andermann F, et al. Focal cortical myoclonus and rolandic cortical dysplasia: Clarification by magnetic resonance imaging. Ann Neurol 1988; 23: 317-325.

9. Marchal G, Andermann F, Tampieri D, et al. Generalized cortical dysplasia manifested by diffusely thick cerebral cortex. Arch Neurol $1989 ; 46: 430-434$.

10. Barth PG. Disorders of cerebral migration. Can J Neurol Sci 1987; 14: 1-16.

11. Rakic P. Defects of neuronal migration and the pathogenesis of cortical malformations. I $n$ : Boer GJ, Feenstra MGP, Mirmiran M, et al., eds. Progress in Brain Research, vol. 73. Elsevier Science Publishers BV (Biomedical Division), 1988; 15-37.

12. Rakic P. Specification of cerebral cortical areas. Science 1988; 241 : 170-176.

13. Stewart RM, Richman DP, Caviness VS Jr. Lissencephaly and pachygyria: An architectonic and topographical analysis. Acta Neuropath (Berl) 1975; 31: 1-12.

14. Crome L. Pachygyria J Pathol Bact 1956; 71: 335-352.

15. Friede RL. Dysplasias of cerebral cortex. In: Friede RL, ed. Developmental Neuropathology, Wien: Springer-Verlag 1975; 297-313.

16. Jakob H. Genetisch verschiedene Gruppen entwicklungsgestörter Gehime. Z ges Neurol Psychiat 1936; 155: 1-39.

17. Jakob $\mathrm{H}$. Genetisch verschiedene Gruppen entwicklungsgestörter Gehirne. Z ges Neurol Psychiat 1938; 160: 615-648. 
18. Jellinger K, Rett A. Agyria-Pachygyria (Lissencephaly syndrome). Neuropäediatrie 1976; 7: 66-91.

19. Matell M. Ein Fall von Heterotopie der grauen Substanz in den beiden Hemispheren des Großhirns. Arch Psychiat Nervenkr 1893; 25: 124-136.

20. Vogt H, Astwaraturow M. Uber angeborene Kleinhirnerkrankrungen mit Beiträgen zur Entwicklungsgeschichte des Kleinhirns. Arch Psychiat Nervenkr 1912; 49: 75-201.

21. Wiest WD, Hallervorden J. Migrationshemmungen in Groß-und Kleinhirn. Dtsch Z Nervenheilk 1958; 178: 224-238.

22. Barkovitch AJ, Jackson DE, Boyer RS. Band heterotopias: A newly recognized neuronal migration anomaly. Radiology 1989; 171: 455-458.

23. Dobyns WB. The neurogenetics of lissencephaly. In: Johnson WG, ed. Neurogenetic Diseases. Neurologic Clinics, vol. 7. Philadelphia: W.B. Saunders Company 1989; 89-105.

24. Dobyns WB, Ledbetter DH. Clinical manifestations and causal heterogeneity in isolated lissencephaly sequence. Am J Hum Genet 1989; 44: A44.

25. Kuzniecky R, Andermann F, Tampieri D, et al. Bilateral central macrogyria: Epilepsy, pseudobulbar palsy, and mental retardation - A recognizable neuronal migration disorder. Ann Neurol 1989; 25: 547-554.

26. Gotman J, Ives JRZ, Gloor P. Monitoring at the Montreal Neurological Institute. In: Gotman J, Ives JRZ, Gloor P, eds. Long-term Monitoring in Epilepsy; Amsterdam: Elsevier 1985; 327-340.

27. Jones-Gotman $\mathbf{M}$. Commentary: Evaluation: testing hippocampal function. In: Engel J Jr, ed. Surgical Treatment of the Epilepsies, New York: Raven Press; 1987: 203-211.

28. Milner B. Psychological aspects of focal epilepsy and its neurosurgical management. In: Purpura $\mathrm{D}$, Penry K, Walter R, eds. Neurosurgical management of the epilepsies. Advances in Neurology, vol. 8. New York: Raven Press, 1975; 299-321.

29. Taylor DC, Falconer MA, Bruton CJ, et al. Focal dysplasia of the cerebral cortex in epilepsy. J Neurol Neurosurg Psychiatry 1971; 34: 369-387.

30. Perot P, Weir B, Rasmussen T. Tuberous sclerosis: Surgical therapy for seizures. Arch Neurol 1966; 15: 498-506.

31. Graff-Radford NR, Bosch EP, Stears JC, et al. Developmental Foix-Chavany-Marie syndrome in identical twins. Ann Neurol 1986; 20: 632-635.

32. Ambrosetto G, Tassinari CA. Sleep-related focal motor seizures in bilateral central macrogyria. [Letter]. Ann Neurol 1990; 28: 841 .
33. Andermann F, Kuzniecky R, Tampieri D, et al. Sleep-related focal motor seizures in bilateral central macrogyria [Letter]. Ann Neurol 1990; 28: 841-842.

34. Becker PS. Developmental Foix-Chavany-Marie syndrome: Polymicrogyria or macrogyria? Ann Neurol 1990; 27: 693 (letter).

35. Kuzniecky R, Andermann F, Fusco L, et al. Corpus callosotomy in the management of the congenital bilateral perisylvian syndrome. Epilepsia 1990; 31: 639.

36. Palmini A, Andermann E, Andermann F. Familial congenital bilateral perisylvian syndrome: genetic determination of a localized neuronal migration disorder. Ann Neurol 1991 (submitted for publication).

37. Livingston JH, Aicardi J. Unusual MRI appearance of diffuse subcortical heterotopia or "double cortex" in two children. J Neurol Neurosurg Psychiatry 1990; 53: 617-620.

38. Palmini A, Andermann F, Aicardi J, et al. Diffuse cortical dysplasia or the "double cortex" syndrome: The clinical and epileptic spectrum in 10 patients. Neurology 1991, in press.

39. Evrard P, Caviness VS Jr, Prats-Vinas J, Lyon G. The mechanism of arrest of neuronal migration in the Zellweger malformation: An hypothesis based upon cytoarchitectonic analysis. Acta Neuropathol 1978; 41: 109-117.

40. Richman DP, Stewart RM, Hutchinson JW, et al. Mechanical model of brain convolutional development. Science 1975; 189: 18-21.

41. Pinard JM, Motte J, Dulac O. Subcortical laminar heterotopia with MRI "double cortex" image and lissencephaly in two families: A same genetic dominant origin? Ann Neurol 1991 (submitted for publication).

42. Townsend J, Nielsen S, Malamud N. Unilateral megalencephaly: hamartoma or neoplasm? Neurology 1975; 25: 448-453.

43. Vigevano F, Bertini E, Boldrini R, et al. Hemimegalencephaly and intractable epilepsy: Benefits of hemispherectomy. Epilepsia 1989; 30: 833-843.

44. Palmini A, Andermann F, Olivier A, et al. Focal neuronal migration disorders and intractable epilepsy: A study of 30 patients. Ann Neurol 1991, in press.

45. Palmini A, Andermann F, Olivier A, et al. Focal neuronal migration disorders and intractable epilepsy: Results of surgical treatment. Ann Neurol 1991, in press. 